\title{
Association of Intrinsic Factors with Non-contact Low Back Pain Among Fast Bowlers Aged between $15-19$ Years in Division 1 Boys' Schools in Colombo
}

Udeesh Satheesha Jayasinghe ( $\nabla$ udeesh27@gmail.com )

General Sir John Kotelawala Defence University

Imasha Swaris

General Sir John Kotelawala Defence University

Diluka Weerasooriya

General Sir John Kotelawala Defence University

Dushan Mayura

General Sir John Kotelawala Defence University

Sachinda Bandara

General Sir John Kotelawala Defence University

Kavindi Disanayake

General Sir John Kotelawala Defence University

Angage Dilani Priyashanthi Perera

General Sir John Kotelawala Defence University

Research note

Keywords: Intrinsic factors, Non-contact low back pain, Fast bowlers, Age 15-19 years

Posted Date: October 1st, 2020

DOI: https://doi.org/10.21203/rs.3.rs-65463/v1

License: (a) (i) This work is licensed under a Creative Commons Attribution 4.0 International License.

Read Full License 


\section{Abstract}

Objective: Cricket fast bowlers are identified as the greatest injury risk players who are more prone to sustain with low back pain (LBP). The current study was aimed to investigate how intrinsic factors associate with LBP among fast bowlers aged between 15-19 years. A descriptive cross-sectional study was conducted with one hundred and two (102) fast bowlers in Colombo division 1 boys' schools in Sri Lanka. Bowlers were prospectively monitored over the competition period of 2019 cricket season and the demographic data, severity of LBP, general characteristics and intrinsic factors related data were recorded.

Results: Thirty-seven (43.5\%) of the subjects were presented with LBP. Reduction of quadriceps strength of dominant side, hamstring strength of non-dominant side and increased ankle dorsiflexion of nondominant side were found to be significantly associated with non-contact LBP $(P<0.05)$. There were significant differences for the quadriceps strength of dominant side and hamstring strength and ankle dorsiflexion of non-dominant side between the fast bowlers with and without LBP. The results indicated that reduced quadriceps muscle strength of dominant side, reduced hamstring muscle strength and high ankle dorsiflexion of non-dominant side have an important role in predisposing a fast bowler to have an increase in non-contact LBP.

\section{Introduction}

Cricket fast bowlers are more prone to get injuries due to their heavy workload and repetitive stress acts through body alignments which results from ground reaction force (GRF) [1]. GRF will result stress force on lumbar spine through foot, ankle, knee and hip kinetic chain. Incorrect techniques, less physical preparation, high intensity and excessive workload will put fast bowlers at a high risk of having noncontact LBP [2,3]. The prevalence of injury among fast bowlers was $8 \%$ in the international cricket [4]. Australian, South African, English, West Indian and Indian bowlers experienced more injuries (41.3\%) and among young fast bowler's lumbar stress fractures is the most severe condition [5]. Lower limbs and lower back strains and sprains are at greatest injury incidence in Sri Lankan junior cricket bowlers with $20.3 \%$ and match injury incidence rate is 5.7 [6].

Non-contact LBP is the occurrence of pain without any collision mechanism with an external force; players or objects [7]. Intrinsic factors are considered as factors which are related to players themselves (techniques, structural alignment) for being injured. These factors are related with quadriceps strength, hamstring flexibility, hip internal rotation, ankle dorsiflexion, back muscles strength and trunk movements [8].

Thus, the aim of this study was to examine the association of intrinsic factors with non-contact LBP among fast bowlers aged between 15-19 years in division 1 boy's schools in Colombo district. School fast bowlers those who are yet having time to mature physically are susceptible for injuries and they are the ones who are going to represent the national team in near future. This research will open up the 
pathways to evolving of many other research topics related to school level cricketers about what they are going to face in the future.

\section{Methods}

\section{Subjects}

This descriptive cross-sectional study was conducted with 102 subjects in the competition period of 2019 cricket season among all the division 1 boys' schools in Colombo. Among them, the subjects with a history of any neurological disorders, cardio-vascular diseases, experience of pain in any area that different from lower back region, complaint of pain more than 6 in the Numerical Pain Rating Scale (NPRS) of any joint which was used in the test procedures, intolerable pain during the measurement gaining procedures and the subjects with contact LBP were excluded.

The data provided by the fast bowlers were collected and recorded following taking the written informed consent and explaining the procedure of the research. Selected subjects performed a 5 minutes warm up session and 5 minutes static stretching exercises to minimize the variability and the standard error of the measurements by reducing the impact of different muscle temperature on muscle flexibility. There was one specific examiner all the time to examine the specific task to avoid the inter-examiner error. 30 seconds rest was allowed during each trial and 2-3 minutes resting time was allowed during each station.

Before administrating the questionnaire (Additional file 1) which was developed for this study as the data collection tool for the study participants, it was administered to randomly select 10 male fast bowler between 15-19 years old, who were outside the defined study area.

\section{Measurements and procedures}

Back extensor strength was measured by using Back-Leg-Chest dynamometer. Subject was asked to stand with both feet on base in lined with erect trunk and bent knees, as hands were able to grasp the chain of the dynamometer at a proper height. Adjust chain to accommodate a suitable height for the test. The body would be inclined forward about 60 degrees. Then subject was asked to straighten the knees, lift the chain, and apply a pulling force on the handle. Subject should lift in a gradual vertical motion.

Quadriceps and hamstring muscle strength and muscle strength were measured by using a calibrated modified sphygmomanometer. When taking the measurement of quadriceps strength, athlete was sitting in 90 degrees flexed hip and 90 degrees flexed knee position. When assessing the hamstring strength, the athlete was in prone lying position with knees extended fully. During the test, athletes were asked to perform maximum isometric contractions. The modified-modified Schober was used to measure ROM of trunk flexion and extension [9]. Trunk lateral flexion was measured by using the fingertip-to-floor method 
[10]. Hip internal rotation and external rotation were measured by using goniometer modified with a spirit level while lunge test was used to assess the ROM of ankle dorsiflexion.

Hamstring flexibility was measured by using sit and reach test. Athlete has to reach forward as much as possible along the measuring line and touch the extreme point. Intensity of pain was measured by NPRS in interviewer administered questionnaire.

\section{Statistical analysis}

All statistical analysis was conducted by the SPSS version 22. As the variable data did not express a normal distribution across the sample, nonparametric tests were used to analyze the data. Mann Whitney $U$ test was used to assess the difference between the fast bowlers with and without LBP. Spearman correlation was used to assess the association between two variables. $\mathrm{P}<0.05$ was considered for significant level.

\section{Results}

Eighty-five (85) fast bowlers were recruited and 17 were excluded from a preliminary sample of 102 . The mean age of study population was $16.6 \pm 1.0$ years. The Prevalence of LBP was $43.5 \%$ in the study population. The majority of the population is with right arm bowlers (91\%) while the remaining of the population (9\%) is with left arm. Distribution of the type of seeking health care professionals by fast bowlers with LBP is shown in Additional file 2: Figure S1.

As the data did not show a normal distribution, non-parametric median values were used to assess the difference between two variables (Table 1). The age, bowling experience, training period, height, weight and BMI did not show any significant difference between the fast bowlers with and without LBP $(p>0.05)$. 
Table 1

Distribution of general characteristics of the study population $(n=85)$

\begin{tabular}{|llll|}
\hline & Median & & \\
\hline Variable & With LBP $(\mathbf{n}=\mathbf{3 7})$ & Without LBP $(\mathbf{n}=\mathbf{4 8})$ & p-value \\
\hline Age (years) & 17.0 & 17.0 & 0.81 \\
\hline Bowling experience (years) & 6.0 & 6.0 & 0.83 \\
\hline Training period (hours per week) & 2.0 & 3.0 & 0.08 \\
\hline Height (meters) & 1.7 & 1.7 & 0.58 \\
\hline Weight (kilograms) & 56.3 & 61.7 & 0.17 \\
\hline Body Mass Index $\left(\mathrm{kg} / \mathrm{m}^{-2}\right)$ & 20.0 & 21.1 & 0.26 \\
\hline $\begin{array}{l}\text { p-value: significant level result from Mann Whitney U test; LBP: Low Back Pain; } \mathrm{kg} / \mathrm{m}^{-2} \text { : kilograms per } \\
\text { square meter }\end{array}$ & & \\
\hline
\end{tabular}

Table 2 reflects the intrinsic factors of the study population with and without LBP. It showed a highly significant difference only for the quadriceps strength of dominant side, hamstring strength and ankle dorsiflexion of non-dominant side between the fast bowlers with and without LBP $(p<0.05)$. However, no significant difference was identified for other intrinsic factors between the fast bowlers with and without $\operatorname{LBP}(p<0.05)$. 
Table 2

Distribution of intrinsic factors of the study population $(n=85)$

\begin{tabular}{|c|c|c|c|}
\hline \multirow[b]{2}{*}{ Variable } & \multicolumn{3}{|l|}{ Median } \\
\hline & $\begin{array}{l}\text { With LBP } \\
(n=37)\end{array}$ & $\begin{array}{l}\text { Without LBP } \\
(n=48)\end{array}$ & $\begin{array}{l}\text { p- } \\
\text { value }\end{array}$ \\
\hline $\begin{array}{l}\text { Quadriceps strength of non-dominant side } \\
\text { (mmHg) }\end{array}$ & 142.0 & 152.5 & 0.12 \\
\hline Quadriceps strength of dominant side (mmHg) & 147.0 & 163.0 & $0.01 *$ \\
\hline Hamstring strength of non-dominant side $(\mathrm{mmHg})$ & 101.0 & 117.0 & $0.04 *$ \\
\hline Hamstring strength of dominant side $(\mathrm{mmHg})$ & 108.0 & 119.0 & 0.35 \\
\hline Back extensor muscles strength (kg) & 72.0 & 85.0 & 0.11 \\
\hline ROM of trunk Flexion $(\mathrm{cm})$ & 6.5 & 6.5 & 0.86 \\
\hline ROM of trunk extension (cm) & 3.2 & 3.5 & 0.67 \\
\hline $\begin{array}{l}\text { ROM of non-dominant side trunk lateral flexion } \\
(\mathrm{cm})\end{array}$ & 21.2 & 21.5 & 0.33 \\
\hline ROM of dominant side trunk lateral flexion $(\mathrm{cm})$ & 21.0 & 21.0 & 0.44 \\
\hline ROM of non-dominant side trunk rotation $(\mathrm{cm})$ & 5.5 & 6.3 & 0.54 \\
\hline ROM of dominant side trunk rotation $(\mathrm{cm})$ & 6.5 & 7.1 & 0.20 \\
\hline $\begin{array}{l}\text { Hip internal rotation of non-dominant side } \\
\left(\text { degrees } /^{\circ}\right)\end{array}$ & 38.0 & 36.0 & 0.45 \\
\hline Hip internal rotation of dominant side $\left(\right.$ degrees $/{ }^{\circ}$ ) & 36.0 & 35.5 & 0.21 \\
\hline Ankle dorsiflexion of non-dominant side $(\mathrm{cm})$ & 13.9 & 15.2 & $0.04^{*}$ \\
\hline Ankle dorsiflexion of dominant side $(\mathrm{cm})$ & 14.9 & 15.1 & 0.33 \\
\hline Hamstring flexibility (cm) & 32.2 & 32.3 & 0.31 \\
\hline \multicolumn{4}{|c|}{$\begin{array}{l}\text { p-value: significant level result from Mann Whitney U test; LBP: Low Back Pain; ROM: Range of } \\
\text { Motion }\end{array}$} \\
\hline
\end{tabular}

Association of general characteristics with LBP of the study population was evaluated in Additional file 3: Table S1. There were negative correlations for the age, body mass index and training period and a positive correlation for the bowling experience with LBP of the study population which was insignificant.

Table 3 shows the association of intrinsic factors with the LBP of the study population. Quadriceps strength of dominant side, hamstring strength and ankle dorsiflexion of non- dominant side was significantly negatively correlated with the LBP $(p<0.05)$. Hip internal rotation of dominant and non- 
dominant sides, ankle dorsiflexion of dominant side, hamstring flexibility were insignificant positively correlated with the LBP $(p>0.05)$. Quadriceps strength of non-dominant side, hamstring strength of dominant side, ROM of trunk flexion, extension, rotations and non-dominant side lateral flexion were negatively correlated with the LBP, while ROM of dominant side lateral flexion was positively correlated with the LBP. However, none of the parameters were not significantly associated with the LBP $(p>0.05)$.

Table 3

Association of intrinsic factors with Low Back Pain of the study population

\begin{tabular}{|c|c|c|}
\hline Variable & $r_{\text {sp }}$ & p-value \\
\hline Quadriceps strength of non-dominant side (mmHg) & -0.18 & 0.11 \\
\hline Quadriceps strength of dominant side (mmHg) & $-0.34^{\star}$ & $0.01 *$ \\
\hline Hamstring strength of non-dominant side (mmHg) & $-0.28^{\star}$ & $0.01 *$ \\
\hline Hamstring strength of dominant side $(\mathrm{mmHg})$ & -0.15 & 0.17 \\
\hline Back extensor muscles strength $(\mathrm{kg})$ & -0.20 & 0.06 \\
\hline ROM of trunk Flexion (cm) & -0.01 & 0.91 \\
\hline ROM of trunk extension $(\mathrm{cm})$ & -0.09 & 0.42 \\
\hline ROM of non-dominant side trunk lateral flexion $(\mathrm{cm})$ & -0.05 & 0.64 \\
\hline ROM of dominant side trunk lateral flexion $(\mathrm{cm})$ & 0.09 & 0.41 \\
\hline ROM of non-dominant side trunk rotation (cm) & -0.07 & 0.51 \\
\hline ROM of dominant side trunk rotation $(\mathrm{cm})$ & -0.18 & 0.11 \\
\hline Hip internal rotation of non-dominant side $\left(\right.$ degrees $/{ }^{\circ}$ ) & 0.08 & 0.46 \\
\hline Hip internal rotation of dominant side (degrees $/{ }^{\circ}$ ) & 0.14 & 0.21 \\
\hline Ankle dorsiflexion of non-dominant side $(\mathrm{cm})$ & $0.26 *$ & $0.02^{\star}$ \\
\hline Ankle dorsiflexion of dominant side $(\mathrm{cm})$ & 0.13 & 0.25 \\
\hline Hamstring flexibility (cm) & 0.11 & 0.31 \\
\hline \multicolumn{3}{|c|}{$\begin{array}{l}r_{\mathrm{sp}} \text { : Spearman's correlation coefficient; p-value: significant level result from Spearman's correlation } \\
\text { test; ROM: Range of Motion }\end{array}$} \\
\hline \multicolumn{3}{|l|}{ * $\mathrm{p}<.05$ : significant } \\
\hline
\end{tabular}

\section{Discussion}

This study describes the associated intrinsic factors and how it relates to the prevalence of non-contact LBP in adolescent male fast bowlers playing for division 1 Colombo schools aged between 15-19 years. Previously some studies had been conducted, but focusing only one or two intrinsic factors related to this 
topic. This is the first research study presenting associated intrinsic factors to fast bowlers' low back pain in Sri Lankan region.

Similar to present study, Foster et al. [11] also explained that the age of adolescent the fast bowlers might be susceptible for high incidence of lower back injuries (LBI) due to incomplete ossification of neural arches of lumbar vertebrae. A study of three dimensional measurement of lumbar spine kinematics in fast bowlers emphasized that there was no significant relationship between lumbar injuries and all the lower lumbar movements [12]. With regards to that, excessive trunk lateral flexion has been identified by analyzing dynamic biomechanics, as a risk factor of low back injuries in adolescent cricket pace bowlers [7].

There was no significant difference in hip internal or external rotation between adolescent fast bowlers with or without LBP [13]. However, Dennis et al. [14] evaluated that reduction of hip internal rotation of dominant side had significant association with reduction of LBI risk in male adult fast bowlers. Higher peak vertical GRF which is considered as the main contributing factor to the lumbar stress fractures among fast bowlers is associated with a small plantar angle due to increased ankle dorsiflexion and reduced hip flexion [15]. At the delivery stride, a fast bowler has to absorb a maximum GRF of nine times of the body weight during the initial front foot landing [16]. Conversely, restriction in foot and ankle motion can be associated with prevalence of LBP [17].

Weakened quadriceps muscle strength can be lead to LBI [11]. Normally during run up phase, the generated GRF was absorbed by the knee joint and the lumbar spine and the reduction of quadriceps muscle strength resulted reduction of shock absorption on the knee joint and increased the force on the lumbar spine [18]. In contrast, a study interpreted that quadriceps muscle strength of non-dominant side was associated with LBP of young fast bowlers [11]. In fast bowlers, quadriceps and hamstrings muscles are repeatedly contracted eccentrically and concentrically through the run up phase and a peak vertical GRF and a horizontal GRF exert on the dominant side leg on delivery stride [19]. It was evident that reduced hamstring muscle strength cause LBP. When hamstrings weakened than quadriceps muscle, it resulted a downward pull of pelvis that cause hyperextension of lumbar spine. Due to the changed vertebral angle of the spine, the pressure placed on intervertebral discs was increased which would lead to LBI [20].

There were no significant differences existed between strength of back extensor muscles with and without LBP groups in fast bowlers (mean age $=17.9$ years) [21]. Some postural deficits caused by genetic factors may predispose an individual to develop the injuries of the lumbar spine, especially when young and playing a high-risk sport like cricket fast bowling [22,23].

Children are more susceptible to overuse injuries than adults due to the effect on their immature growth cartilages and as children become more heavily involved in cricket [24].

LBP is not associated with impaired hamstring flexibility, stiffness [25] or hamstring muscle length [26]. MassoudArab et al. [27] further described that there is no significant difference in hamstring muscle 
length with and without sacroiliac joint dysfunction. Some controversial findings stated that lumbar disc abnormalities had an association with reduced hamstring flexibility [8].

\section{Conclusion}

The findings of this study revealed that none of the general characteristics which are age, BMI, training period and bowling experience did not contribute to develop LBP symptoms among the adolescent fast bowlers aged between 15-19 years. The higher muscular strength of dominant side quadriceps muscle and non-dominant side hamstring muscle having less probability to develop LBP. Likely, the fast bowlers with higher non-dominant side ankle dorsiflexion are more prone to having LBP.

\section{Limitations}

To the best of our knowledge, this was the first study to investigate the associated intrinsic factors to adolescent male fast bowlers' low back pain in Sri Lankan region., however there were a number of limitations. This study was limited to the male population though the game of cricket is now played more commonly by females in Sri Lanka. Further studies should be carried out to cover all areas in Sri Lanka including the Division 02 and Division 03 schools to enhance the sample size.

\section{Abbreviations}

BMI - Body Mass Index

GRF - Ground Reaction Force

LBP - Low Back Pain

LBI - Lower Back Injuries

NPRS - Numerical Pain Rating Scale

\section{Declarations}

\section{Ethics approval and consent to participate}

A written informed consent was obtained from all the participants and their parents and the ethical clearance was obtained from the Ethics Review Committee, Faculty of Medicine, General Sir John Kotelawala Defence University.

\section{Consent for publication}

Not applicable. 


\section{Availability of data and materials}

Since the privacy of research participants may be compromised, we cannot make the information publicly available.

\section{Competing interests}

The authors declare that they have no competing interests.

\section{Funding}

None

\section{Authors' contributions}

USJ and ADPP contributed to manuscript writing, developing study concept and design, data acquisition and data analysis; USJ, IS, DW, DM, SB and KD contributed to data acquisition. All authors read and approved the final manuscript.

\section{Acknowledgements}

The authors would like to express their sincere gratitude to the supervisor of this research Mrs. ADP Perera, Senior lecturer, Department of Physiotherapy, Faculty of Allied Health Sciences, General Sir John Kotelawala Defense University for the tremendous guidance and the support given in every step throughout the process of this study.

\section{References}

1. Elliott BC. Back injuries and the fast bowler in cricket. Journal of sports sciences. 2000 Jan 1;18(12):983-91.

2. Mathew $A$, Rai $S$, Kumar D. Low back injuries in fast bowlers: A literature review. International Journal of Allied Medical Sciences and Clinical Research. 2016;4(2):184-195.

3. Thiagarajan KA, Parikh T. Anees Sayed Cricket Biomechanics Analysis of Skilled and Ameteur Fast Bowling Technique. Journal of Postgraduate Medicine, Education and Research. 2015:173-81.

4. Mount S, Moore I, Ranson C. Injury types and rates in an international cricket team: Application of subsequent injury categorisation. British journal of sports medicine. 2014 Apr 1;48(7):642-.

5. Pardiwala D, Rao N, Varshney A. Injuries in Cricket. Sports Health: A Multidisciplinary Approach. 2017;10(3):217-222. 
6. Gamage PJ, Fortington LV, Kountouris A, Finch CF. Match injuries in Sri Lankan junior cricket: A prospective, longitudinal study. Journal of science and medicine in sport. 2019 Jun 1;22(6):647-52.

7. Forrest MR, Hebert JJ, Scott BR, Brini S, Dempsey AR. Risk factors for non-contact injury in adolescent cricket pace bowlers: a systematic review. Sports medicine. 2017 Dec 1;47(12):2603-19.

8. Olivier B, Stewart A, Taljaard T, Burger E, Brukner P, Orchard J, Gray J, Botha N, Mckinon W. Extrinsic and intrinsic factors associated with non-contact injury in adult pace bowlers: a systematic review protocol. JBI database of systematic reviews and implementation reports. 2015 Jan 1;13(1):3-13.

9. Williams R, Binkley J, Bloch R, Goldsmith $\mathrm{CH}$, Minuk T. Reliability of the modified-modified Schöber and double inclinometer methods for measuring lumbar flexion and extension. Physical therapy. 1993 Jan 1;73(1):26-37.

10. Frost M, Stuckey S, Smalley LA, Dorman G. Reliability of measuring trunk motions in centimeters. Physical therapy. 1982 Oct 1;62(10):1431-7.

11. Foster D, John D, Elliott B, Ackland T, Fitch K. Back injuries to fast bowlers in cricket: a prospective study. British journal of sports medicine. 1989 Sep 1;23(3):150-4.

12. Burnett AF, Barrett CJ, Marshall RN, Elliott BC, Day RE. Three-dimensional measurement of lumbar spine kinematics for fast bowlers in cricket. Clinical Biomechanics. 1998 Dec 1;13(8):574-83.

13. Bayne H, Elliott B, Campbell A, Alderson J. Lumbar load in adolescent fast bowlers: a prospective injury study. Journal of Science and Medicine in Sport. 2016 Feb 1;19(2):117-22.

14. Dennis RJ, Finch CF, Mclntosh AS, Elliott BC. Use of field-based tests to identify risk factors for injury to fast bowlers in cricket. British Journal of Sports Medicine. 2008 Jun 1;42(6):477-82.

15. Worthington P, King M, Ranson $C$. The influence of cricket fast bowlers' front leg technique on peak ground reaction forces. Journal of Sports Sciences. 2013 Feb 1;31(4):434-41.

16. Krishna SA, Alwar TK, Sayed A, Gnanavel MB, Sivaraman A. Are Indian Cricket Fast Bowlers At Risk Of Injury?-A 3d Biomechanical Investigation: 1378 Board\# 53 June 1800 AM-930 AM. Medicine \& Science in Sports \& Exercise. 2017 May 1;49(5S):374-5.

17. Brantingham JW, Gilbert JL, Shaik J, Globe G. Sagittal plane blockage of the foot, ankle and hallux and foot alignment-prevalence and association with low back pain. Journal of chiropractic medicine. 2006 Dec 1;5(4):123-7.

18. Cai C, Kong PW. Low back and lower-limb muscle performance in male and female recreational runners with chronic low back pain. Journal of Orthopaedic \& Sports Physical Therapy. 2015 Jun;45(6):436-43.

19. Feros SA. The Determinants and Development of Fast Bowling Performance in Cricket. An Internasional Perspective on Topics in Sports Medicine and Sports Injury. 2015 Sep.

20. de Sousa CS, de Jesus FL, Machado MB, Ferreira G, Ayres IG, de Aquino LM, Fukuda TY, Gomes-Neto M. Lower limb muscle strength in patients with low back pain: a systematic review and metaanalysis. Journal of musculoskeletal \& neuronal interactions. 2019;19(1):69. 
21. Elliott $B C$, Hardcastle $P H$, Burnett $A E$, Foster $D H$. The influence of fast bowling and physical factors on radiologic features in high performance young fast bowlers. Research in Sports Medicine: An International Journal. 1992 Feb 1;3(2):113-30.

22. Millson HB, Gray J, Stretch RA, Lambert MI. Dissociation between back pain and bone stress reaction as measured by CT scan in young cricket fast bowlers. British journal of sports medicine. 2004 Oct 1;38(5):586-91.

23. Cyron BM, Hutton WC. The fatigue strength of the lumbar neural arch in spondylolysis. The Journal of Bone and Joint Surgery. British volume. 1978 May;60(2):234-8.

24. Harris I. The prevalence of low back pain in cricketers-An undergraduate epidemiological study. South African Journal of Physiotherapy. 1993 Nov 30;49(4):65-6.

25. Hori $\mathrm{M}$, Hasegawa $\mathrm{H}$, Takasaki $\mathrm{H}$. Comparisons of hamstring flexibility between individuals with and without low back pain: systematic review with meta-analysis. Physiotherapy Theory and Practice. 2019 Jul 19:1-24.

26. Nourbakhsh MR, Arab AM. Relationship between mechanical factors and incidence of low back pain. Journal of Orthopaedic \& Sports Physical Therapy. 2002 Sep;32(9):447-60.

27. MassoudArab A, RezaNourbakhsh M, Mohammadifar A. The relationship between hamstring length and gluteal muscle strength in individuals with sacroiliac joint dysfunction. Journal of Manual \& Manipulative Therapy. 2011 Feb 1;19(1):5-10.

\section{Supplementary Files}

This is a list of supplementary files associated with this preprint. Click to download.

- FigureS1.jpg

- TableS1.docx

- InterviewerAdministeredQuestionnaire.pdf 